Fecha de recepción: febrero 2019 Fecha de aceptación: marzo 2019 Versión final: mayo 2019

\section{Un animal que hurga. Procesos de creación en la fotografía argentina}

Denise Labraga *

Resumen: Este artículo se adentra en la reflexión acerca de algunos aspectos vinculados a los procesos de la creación artística en las artes visuales, y específicamente en la fotografía argentina.

Las formas de llegar a la obra y desarrollar el acto de creación son múltiples y personales. La propuesta es asomarnos a observar el escenario local y pensar en sus particularidades, sus marcas y sus problemáticas.

Palabras clave: Fotografía - creación artística - proceso - artes visuales

[Resúmenes en inglés y portugués en la página 94]

${ }^{(*)}$ Fotógrafa profesional (Motivarte). Diplomada en Investigación y Conservación Fotográfica Documental (Universidad de Buenos Aires). Realizó estudios en Ciencias de la Comunicación (Universidad de Buenos Aires) y actualmente se encuentra cursando el Programa de Conservación del Patrimonio Fotográfico (Centro de Fotografía de Montevideo).

\title{
Introducción
}

Este escrito breve es un ejercicio de aproximación. Es parte de una investigación en curso sobre los procesos de creación en las artes visuales, y específicamente en la fotografía argentina. En el momento de elaboración de este artículo se cumple para mí una etapa de una década, desde que concluí mis estudios formales y comencé a hacerme preguntas insistentes sobre este asunto, participar de clínicas y talleres, realizar entrevistas, completar decenas de formularios de aplicación, visitar estudios y sostener numerosas conversaciones trasnochadas en torno al crear. Llegado este punto, me propongo sistematizar mis observaciones sin buscar describir una generación, porque una generación es un cristal roto, no es más que un concreto horizonte de pertenencia que se valida por sobre su antecesor, como en una competencia o una cadena de montaje.

En esta oportunidad, decido no usar nombres al citar frases de entrevistas y conversaciones, sino sólo iniciales, porque entendí que no me interesa especialmente posicionar la palabra del artista consagrado como cita de autoridad. En cambio, mi búsqueda repara en la 
experiencia del artista visual en sentido amplio, y en cualquier etapa de desenvolvimiento en que se encuentre su carrera. Sin desestimar las diferencias que sí existen, a través de esta estrategia descubrí que si se rasca un poco más, debajo de la superficie aparecen algunas preocupaciones, temores y satisfacciones comunes, ya sea que el artista en cuestión se encuentre dando sus primeros pasos, o bien realizando muestras retrospectivas y recibiendo premios a la trayectoria.

La posibilidad de hablar hoy con naturalidad de la fotografía como disciplina dentro de las artes visuales es el resultado de un proceso lento y no exento de complejidad. Su incorporación definitiva en el sistema del arte se dio a través del conceptualismo, "lo cual implica una gran paradoja histórica” según afirma la crítica e investigadora Valeria González (Jastreblansky, 2008). Porque el arte conceptual, en su amplio espectro de tendencias, echó mano de la fotografía (junto con la palabra, la performance y el video) en el marco de una estrategia "anti-artística" que perseguía la intención de manifestarse frente al mercado. En este sentido, el éxito del conceptualismo implica la frustración de esta lucha, pero significó que las obras realizadas sobre soporte fotográfico pasaran a formar parte de las colecciones de arte contemporáneo.

Pensar estos procesos en su complejidad, con sus tensiones, es entender que lo que hoy concebimos como "las artes visuales" es una construcción, pero que podría haber sido otra. Y nos otorga la posibilidad de reconocernos como sujetos activos dentro de la disputa por la legitimación del sentido. Asimismo, la discusión en torno a si una disciplina merece o no un lugar dentro de las artes visuales ha caducado hace rato. Los medios técnicos desplegados no son lo que distingue una obra, sino el campo de problemas que construye. Los medios empleados van a ser, según la intención del artista, los más apropiados para plantear estos problemas.

Por supuesto, el proceso de creación no es uno, ni existen una serie de pasos concretos, ni un modo único del hacer. Las formas de abordar la obra y desarrollar el acto de creación son múltiples y personales. Además, los deseos del artista también se encuentran influidos por una serie de factores ajenos a él: la formación, las demandas del mercado del arte, los certámenes de distinto tipo, el entorno social y político, la obra de otros artistas contemporáneos, etc. Las ideas y valores que nutren la creación se desarrollan en y contra un fondo que está conformado por la educación y las vivencias sociales. Si el contexto social de emergencia de la obra exhibe sus marcas, allí se abrirá el espacio para una significación destacable.

Aunque las indagaciones particulares que aquí propongo remiten directamente a experiencias íntimas y personales, sostengo que el estudio del arte no debe separarse del estudio y comprensión de las sociedades, debe ser emplazado en la trama de relaciones que lo hacen posible.

\section{Polvo en suspensión}

J. I. es artista plástico y trabaja hace varios años utilizando un pigmento de color azul. Un día, cuando salía de su taller después de una jornada de trabajo, notó que había estado dejando un caminito de polvo azulino que lo seguía hasta la puerta de entrada. Esa huella 
lo hizo reflexionar sobre algunas cualidades del material, como la ligereza, la suavidad y la capacidad de suspensión. Cuando volvió a su espacio de trabajo, comenzó a arrojar pequeños puñados de pigmento al aire, que caían grácilmente sobre el bastidor en blanco formando constelaciones polvorientas. Para no perder esta disposición lograda por el azar, J. I. decidió aplicar un fijador que impida que el material se vuele o se deslice. Posteriormente, decidió trazar algunas líneas que unieran aquellas constelaciones, buscando una organización posible dentro del caos. Este procedimiento lo remitió a la física cuántica y las respuestas que brinda esta disciplina a los comportamientos de la naturaleza en su mínima escala. Aquí comenzó otra etapa de su búsqueda, dedicada a la investigación teórica, y a su vez, a la repetición sistemática del procedimiento descripto sobre diferentes superficies. El resultado fue un giro radical en su producción, que lo condujo a una serie de piezas con transparencias, despojadas de marcos y a probar instalaciones en el espacio, lejos de las paredes que habitualmente albergaban su obra.

Normalmente, la creación sobrepasa al tiempo y al espacio, y el momento en el que se está produciendo es una incógnita. No es sencillo tener conciencia de cada paso, cada toma de decisión y cada una de las dudas que atraviesan a este recorrido, porque generalmente todos los sentidos están puestos al servicio de la exploración. Oír el relato tan detallado de J. I. sobre el desarrollo de un proceso de creación fue lo que me impulsó a reunir las preguntas y observaciones que aquí presento.

\section{El campo de batalla}

La página en blanco, situación temida o estado de latencia y potencialidad de todo lo que está a punto de suceder, la metáfora predilecta para hacer referencia al inicio. A este punto de germinación le seguirán una serie de decisiones, o modos de hacer, o accidentes: definir un tema, una motivación, un asunto; o no definirlo en lo absoluto, librarlo al azar, a la pulsión y al deseo. Establecer un método, desarrollar una investigación, indagar en el estado de la cuestión; o simplemente crear compulsivamente y luego editar. Sacar fotos todos los días, salir a sacar fotos, establecer momentos específicos para hacerlo, apropiarse de fotos ajenas, buscadas o encontradas. Delimitar un espacio (el taller, la calle, el estudio, el viaje, la residencia artística). Seleccionar una técnica y una serie de dispositivos, estudiarlos, incorporarlos, adaptarlos; o pensar en los recursos que se requieren para cada nuevo proyecto.

Si se analiza francamente, se puede sortear el pacto de caballeros que sostiene la simulación de que el viejo síndrome de la página en blanco realmente existe. El fotógrafo trabaja a partir de la manera en que se fotografió antes que él. Si este accionar se realiza de manera inconsciente se limitará a repetir las formas establecidas; por el contrario, "si es consciente de esto, tal vez, y no sin lucha, pueda quebrar las rutinas y encontrar algo nuevo. Y allí se continuará la historia de la creación" (Lemagny, 2008, p.110).

El enfrentamiento no es sólo contra el lienzo en blanco (o en este caso, la toma que aún no se ha realizado), toda la historia del arte está por detrás. Lo que se hace es ordenarla, redistribuirla, o intervenirla. La obra surge del diálogo con la historia, desconocer la historia es 
rechazar las condiciones de existencia de la creación. Escatimar el contexto es empobrecer la obra, es quitarle espesor.

Entonces, tal vez, si en algunos casos existe un temor o una sensación de parálisis al momento de crear, esté relacionado con las imágenes del pasado y con la necesidad de romper los clichés para que surja algo nuevo. En este aspecto, normalmente se considera que el artista lucha contra sí mismo, "sin embargo, en primer lugar, el artista lucha contra el mundo" (Berger y otros, 2015, p. 18), contra aquél cúmulo inconmensurable de fotografías que lo precede.

Es en esta lucha -contra las imágenes precedentes y contra el mundo- que tiene lugar el proceso. El campo de batalla puede estar caracterizado por una sensación de vacío, pero este es eminentemente dinámico y activo, sus virtudes principales se definen por la evidencia de que algo sucederá y por la belleza inigualable de lo no escrito. El primer gesto tiene la fuerza "de separar el cielo y la tierra" (Cheng, 2016, p. 183), los pasos siguientes generan todas las formas, como una metamorfosis derivada del primer movimiento. Por último, el momento de difusión o exhibición de la obra anticipa nuevamente el vacío originario.

Llegado este punto, cabe aquí hacer una aclaración: hablar de la página en blanco podría sugerir que tendemos a creer que todo se realiza únicamente en el momento del acto, en el gesto de presionar el disparador, y antes de eso no hay nada. Sin embargo, una idea o incluso una imagen definida pueden aparecérsenos recurrentemente hasta que en un determinado momento se dan las condiciones para su materialización. El momento de investigación previa, la elaboración de bocetos, la confección de listas, pueden tener la apariencia de una fase de quietud, sin embargo, representan la reflexión previa a la acción. A su vez, luego de la toma una fotografía sigue germinando, desarrollándose. Habitualmente, un proyecto se nos presenta con mayor claridad tras haberlo dejado de lado durante un tiempo.

Me pregunto entonces, si la práctica artística está signada por este vaivén incierto (entre otras muchas tensiones que todavía no he mencionado) ¿por qué nos entregamos a ella? O, como exclamó M. C. durante una caminata nocturna: ¿qué es eso tan importante del crear que lo convierte en un desafío para el ser humano? Ante esta pregunta por la pulsión primaria, los abordajes de distintos fotógrafos consultados fueron, naturalmente, diversos:

"Para mi es un misterio y eso es lo que lo hace fascinante. Cuando estoy en ese estado creo no ser yo." (J. B.)

"Si uno se dedica a la creación, de base debe haber una incomodidad. Se trata de un espacio para resolver esa incomodidad." (L. G. P.)

"Nace como un 'algo', cuando la idea no tiene un contexto ni una intención tan precisa. Creo que uno se deja acoger por una idea que ronda y aparece de forma cíclica y escondida tras varias capas de experiencias y tiempo." (F. M.)

En estos comentarios se escabulle una idea de promesa y amenaza, como dos caras indisociables de la misma práctica. Misterio, incomodidad, fascinación, aparición. Aquí lo que queda claro es que el desafío es crear, no crear bien. En cualquier curso o workshop se enseña a sacar buenas fotografías. Para crear bellas imágenes hay recetas, consejos, un camino de aprendizaje. Crear, en cambio, es una decisión de vida, que se realiza con todos los actos de la vida. 


\section{Coeficiente de arte}

Hay determinados problemas que son inherentes al trabajo artístico, como por ejemplo, estar en estado de desequilibrio. Si estuviéramos en estado de equilibrio permanente, no necesitaríamos crear. Una de las fuentes de desequilibrio más recurrentes es el abismo que existe entre una idea y la materialización de esta. $\mathrm{O}$, mejor dicho, la fantasía de una posible correspondencia entre estas dos instancias.

"Between thought and expression lies a lifetime..." [Entre el pensamiento y la expresión yace una eternidad] escribía Lou Reed $(1969,3)$, y es que la realización y la idea están hechas para prolongarse una a la otra, para desbordarse mutuamente. No deberían ser consideradas como dos entidades equivalentes, cada una de ellas encerrada en su armonía estable. Se provocan sin cesar, formando los dos extremos dinámicos de un universo que sólo halla su ligadura en la ejecución del arista.

Duchamp llamó "coeficiente de arte" a "la diferencia entre lo que [el artista] había proyectado y lo que ha realizado. En otros términos -explica-, el 'coeficiente de arte' personal es como una relación aritmética entre lo que es expresado pero estaba proyectado y lo que es expresado inintencionalmente" (Marcadé, 2008, p. 425). Porque aunque toda la tradición del arte conceptual nos indica que idea y obra pueden ser una única cosa (la obra puede ser la idea, sin ninguna referencia a un objeto), a veces están peleadas como dos hermanitas. En el sentido de que no se hace la obra que uno quiere; se trata de querer hasta el fin la obra que se puede, la que puede la época, la que puede un lenguaje, con la pérdida que podría implicar la elaboración material partiendo del plano de la idea:

"Yo boceto. Por ejemplo, si quiero hacer una foto que me imaginé la dibujo para acordarme y para ver si consigo hacer algo parecido. Muchas veces esos dibujos quedan guardados por meses hasta que 'madura' la idea y se dan las condiciones que la posibilitan" explica J.N.

Pero ¿Cómo nace esa idea? ¿Es una aparición recurrente, uno se la cruza repetidas veces hasta que la ve, o de pronto nos echamos a su búsqueda? ¿Hay un proyecto, o hay una idea que aparece de las entrañas y comienza a flotar? ¿Qué importa?

"Las ideas no existen para realizarlas, son para ponerse en movimiento, para salir de la parálisis" afirma A.G., y quizás sea cierto. Algo distinto pasaría si supiéramos olvidar la idea y entregarnos al pequeño fracaso que representa su transformación en el plano material, sin eludir la serie de eventos que se despliegan en la marea que es el proceso. Poco importa que de este recorrido necesariamente se desprenda una obra como pieza material consumada, pero siempre será un escenario que habilita la confluencia de posibilidades de exploración. En el hueco que se expande entre estos dos puntos -la idea y la obra- anida el lenguaje. Cuando uno trabaja con un lenguaje debe tener una estrategia, porque el lenguaje es limitado. Aunque "el terreno de lo fotografiable se extiende mucho más allá de lo que puede ser fotografiado en el sentido técnico del término" (Damish, 2007, p. 57) hay cosas que se transmiten mejor mediante otros recursos, o en la combinación de distintos medios como el video, el texto, el sonido, etc. En estos límites hay un desafío, y a veces es estimulante de 
resolver dentro de los términos del propio lenguaje, como pulseando con él, sabiendo que puede haber derrota.

En general, la escritura se transforma en testigo de esta fase de construcción y destrucción, en forma de diario de proceso o de hoja de ruta. Será la narración y la documentación que darán cuenta del recorrido de la obra, en lo anecdótico o concretamente en un diario que acompañe cada paso. Será el testimonio de las dudas, las decisiones, los cambios de dirección, las citas, los bocetos y los momentos de inspiración.

Las palabras escritas son dibujos que toman forma, adquieren un ritmo, "permiten que las ideas se escurran por distintos surcos, tomen aire, recuperen su centro y finalmente se afiancen" (Wenders, 2016, p. 19). Y es así como muchas veces, frente a la necesidad de explicar un proyecto para presentarlo ante un curador, un jurado o para aplicar a algún programa, hay que detenerse a escribir. Pese al rigor que significa correr contra una fecha tope (más trágicamente conocida como deadline) amenazando en el horizonte, tomarse este trabajo ayuda mucho a ordenar las ideas, a proponerse objetivos concretos y a comenzar a darle cuerpo al asunto.

La escritura también adquiere otra forma en el repertorio de géneros obligados que debe manejar quien se atreva a hacer circular su obra: el statement o la declaración del artista. Hay una preocupación excesiva por tener un modelo de artista. ¿Uno puede hacer un programa del artista que quiere ser, o uno es el artista que le sale? Si uno tiene el mínimo plan es suficiente para ponerse a trabajar. Los planes muy abarcativos pueden ser paralizantes. Estamos afectados por un signo de época que es la exigencia del statement. Uno cree que tiene que preparar su declaración de principios antes de ponerse a trabajar. El riesgo es volverse fiel a ese plan y exigirse darle vida a esa ficción que es el statement.

Esperar verse de cuerpo presente en la obra es el problema generalizado, el asunto es la relación que cada artista asume con este problema, permitiendo o no que ello se ponga por delante del hacer. $\mathrm{Al}$ respecto, J. M. señaló que ante esta exigencia del sistema, "la única manera de ser terrorista es mandar a guardar a todos los statements". No pensar la profesión como algo que hay que conquistar, sino como algo que uno hace y que nos define. Porque cuando se tiene una expectativa demasiado definida de lo que se quiere y de lo que se es, esa identidad se convierte en algo muy rígido que se quiebra con facilidad.

\section{La rendija en el protocolo}

V. B. comenzó a hacer fotografías en formato Polaroid cuando quedó embarazada. Durante ese período se veía limitada de realizar todo el proceso de revelado y ampliación en el laboratorio como lo hacía antes, y le prestaron una cámara instantánea para que la investigara y tratara de seguir tomando fotografías durante ese tiempo. Como resultado de este hecho fortuito, surgió un ensayo fotográfico con características bien distintas a su trabajo previo. En principio, porque originalmente la única premisa que guió ese proyecto era poder seguir tomando fotografías, no había una investigación concreta ni preguntas aparentes que motivaran la toma de las imágenes. $\mathrm{Y}$, en segundo lugar, porque el nuevo dispositivo (y la relación que este propone con el tiempo, con el cuerpo y con la materialidad de la 
imagen) torció naturalmente la forma de ver de la autora y habilitó una poética diferente, demandándole estrategias distintas desde la incomodidad inicial. Con el paso de los meses, ese montoncito de fotos instantáneas hechas "para despuntar el vicio" comenzaron a hacer sentido, a develar una narración posible, habilitando así la posterior fase de edición.

Dar lugar al accidente, al fuera de control y también al error es muy importante para poder romper las reglas. A través de esta rendija en el protocolo surge la transgresión y la posibilidad de que algo se oponga a las pautas que uno mismo establece, dando lugar a escenarios nuevos y abriendo otras puertas de descubrimiento más ligadas a lo intuitivo. Al recibir el Premio Príncipe de Asturias a las Letras, Leonard Cohen dijo: "Si yo supiera de dónde vienen algunas canciones, iría más seguido ahí" (2011). Pero en vano sería intentar comprender la aparición del accidente, del mismo modo que es absurdo tratar de intuir el modo en el que se va a actuar en el futuro. Todo lo que es del orden del imprevisto resulta desconcertante, pero en algunas ocasiones, mirando en perspectiva, sorprende cómo hasta el final los accidentes pueden ser sinceros.

En el proceso se suceden decisiones a través de las cuales se van delineando algunas formas, se decide un camino determinado y se rechazan momentáneamente otros caminos posibles. No hay opción ante la confrontación constante con lo que no fue. No obstante, hacer un registro de lo que se ha descartado nos permite conocer íntimamente el modo en el que producimos. La idea despreciada carga una información muy rica: ¿Qué rechazamos?, ¿qué evadimos?, ¿qué ocultamos? Además, en una etapa posterior, aquella alternativa que fue apartada puede cobrar un nuevo sentido y volver a jugar un rol dentro de un proyecto.

\section{¿Dónde entregan el diploma de artista?}

Para ser un artista visual que realiza obra en soporte fotográfico no se exige algún tipo de formación específica, título habilitante o don innato. Dentro del conjunto de posibilidades de formación en arte, conviven y se entrecruzan una variedad de formatos con sus lógicas particulares: universidades, institutos terciarios, clínicas de obra, cursos, talleres, seminarios, residencias y programas para artistas.

Toda oportunidad de formación puede convertirse en una herramienta para poder pensar qué hacer con eso que se produce, para vincularse con la teoría no solo desde la lectura o la investigación, sino también generándola en la propia práctica artística. Asimismo, un taller, una clínica o una residencia pueden ser el marco ideal para pensar el trabajo de los otros y enriquecer de esta manera el repertorio conceptual común.

En entrevistas realizadas a artistas que habitan distintas provincias del interior del país, aparece como denominador común la formación y actualización como medios de potenciación de la práctica. Ya sea por el perfeccionamiento en algún aspecto técnico o por la posibilidad de "conocer de primera mano la forma de pensar de artistas, críticos y profesores" y así ampliar los imaginarios, como señala R.E.

Comúnmente, esta búsqueda motoriza un tipo de nomadismo o migraciones internas -en algunos casos por períodos acotados y en otros casos de manera permanente- ya sea entre 
provincias vecinas, o hacia Buenos Aires. Becas de movilidad mediante, o sin ellas, estos cruces se dan constantemente y cada experiencia territorial deja un rastro en la producción y la investigación de los artistas.

Los talleres o clínicas funcionan como espacios de acercamiento y vinculación entre pares y también a veces operan como marcos de legitimación, porque generalmente están nucleados por algún referente del campo en cuestión, alguien con experiencia sobre sus hombros. Y aquí reaparece esa palabra a la que renunciamos en la introducción: generación. La formación, en cualquiera de sus variantes formales e informales, puede coquetear con la promesa de ofrecernos pertenecer a una "generación de artistas contemporáneos". Pero ¿quién o quiénes pueden adjudicarse el rol de definir los rasgos que caracterizan a dicha generación? Esta observación no tiene la intención de poner en tela de juicio que toda instancia de educación e intercambio tiene un potencial de gran valor. Sin embargo, resulta oportuno también mencionar que en este campo no existen saberes universales y mucho menos neutrales. Los contenidos dependen en gran medida de los sujetos que se los apropian, los discuten y los nutren; que se preguntan cada tanto qué participación tienen en el establecimiento de los saberes específicos de su quehacer como artista.

A lo largo de la historia se puede identificar una tradición de convivencia entre creadores, motivada por factores diversos, ya sea bajo la forma de comunidades espontáneas, colonias de artistas o academias, etc. Por su parte, las residencias artísticas como modo de cohabitar viven hoy un momento de profusión. Se ofrecen bajo una lógica asociada a la ideología del capitalismo global, que proyecta la fantasía de un mundo sin barreras geográficas y una existencia sin necesidad de raíces.

Se caracterizan por ser una fórmula de producción e investigación que propone un recorte espacio-temporal para ir a renovar las bases, a probar cosas, a dedicarse de tiempo completo a la producción en un modo transfronterizo. Son una suerte de suspensión del ritmo habitual de trabajo, un paréntesis, y una oportunidad de vincularse con un entorno desconocido y ser permeable a lo que esto pueda aportar a nuestras metodologías más instaladas. Moverse un paso al costado de lo predecible del entorno cotidiano puede representar una oportunidad de pararse en el corazón del corazón y redefinir un rumbo o cuestionar certezas adquiridas.

Existen en nuestro país actualmente una gran cantidad de programas de residencia repartidos en las distintas provincias (CIMA, Centro de Investigaciones Artísticas, Colectivo R.A.R.O., Curadora Residencia, Barda del desierto, La Ira de Dios, La Paternal Espacio Proyecto, Manta, Nido Errante, Panal 361, Residencia Corazón Argentina, Tribu de Trueno y URRA, por sólo nombrar algunas), dirigidas por organizaciones independientes, fundaciones o grupos de artistas. Estas propuestas permiten generar escenas comunes de creación, en donde toman relevancia las situaciones locales y lo interdisciplinario.

Las residencias generan prácticas de diálogo ligadas a la lógica del viaje y a los desplazamientos geográficos y mentales. No suponen oposición a instituciones, o invalidación de los circuitos académicos ni confrontación con el mercado.

Existen también otro tipo de experiencias más asociadas a la estructura de grupo con organización horizontal, que muchas veces son la secuela de amistades formadas en ámbitos 
educativos que se sostienen en el tiempo desarrollando sus propias dinámicas. Con mayor o menor formalidad y periodicidad, estos grupos se reúnen para compartir los avances de algún trabajo en proceso, realizan formación interna, intercambian lecturas, organizan proyecciones en espacios itinerantes a través de convocatorias abiertas, o simplemente se juntan para ir a ver exposiciones. Estas asociaciones causales no son promovidas por la aspiración de sumar un ítem más al CV, sino más bien por la genuina búsqueda de modos de aprendizaje diferentes, entre pares, bajo la premisa de poder establecer las propias reglas del intercambio.

Todo este abanico de ofertas, desde la universidad hasta las reuniones de camaradería (con sus pasos intermedios), son opciones que dan respuesta a algunas de las demandas que surgen en diferentes instancias del derrotero de la creación. Quizás, la astucia radique en saber identificar de qué propuestas formativas valerse en cada etapa y cómo complementar las potencialidades y carencias propias de cada una.

\section{El trabajo y el tiempo}

“(...) el trabajo creativo (...) supone la desincronización del tiempo de trabajo respecto del tiempo de exposición de los resultados de esa obra. El trabajo creativo se practica en un tiempo paralelo, de reclusión, en secreto (...)” sostiene Boris Groys (2014, p. 139). Esta fase, donde el flujo del tiempo por venir parece detenerse, significa estar "haciendo algo". Pero no bajo la mitología clásica del esfuerzo solitario, aquella idea romántica del artista iluminado creando en aislamiento, porque como mencioné más arriba, la producción se desarrolla en un juego complejo con su entorno. Se trata de que "(...) cada proyecto es, sobre todo, la declaración de un nuevo futuro que se cree que va a venir una vez que el proyecto haya sido llevado a cabo" (Groys, 2014, p. 73). Producir según este modelo acarrea la peligrosa expectativa de que la creación se de en una línea perfecta de progresión. En este sentido, tanto si el resultado del trabajo es el esperado como si no lo es, ambos casos comparten el afán conclusivo de cerrar (aunque sea temporalmente) el proyecto y re-sincronizar la temporalidad paralela con la temporalidad del entorno social. Siguiendo la línea de análisis que propone Groys, "en ambos casos, esta re-sincronización da lugar a una sensación de malestar, incluso de desánimo" (2014, p. 74). Se resiente la pérdida de la suspensión de la temporalidad paralela, que por definición es el proceso creativo. No obstante, sin negar el vacío que puede generar esta etapa del trabajo, yo considero que no se trata de la clausura o el final de una obra, por el contrario, un proyecto se extiende indefinidamente, ya no está orientada a la construcción de un producto con un resultado específico. En este marco, la exhibición será un nuevo lugar de producción.

La expresión "trabajo" a veces es problemática para el campo del arte. "Hacer" quizás sea más utilizada, es preferible, pero a su vez evade el conflicto. Los artistas producen en una relación directamente proporcional a su capacidad de producción, por lo que la carrera conlleva también la necesidad de realizar acciones para sostener o aumentar esa capacidad (aplicar a becas y concursos, trabajar para una galería, buscar mecenas, entre otras). Entonces, la recompensa por producir será la posibilidad de seguir produciendo. 
Es bastante frecuente que los artistas no logren definirse, sino que más bien cuenten lo que están haciendo en un determinado momento. Por ejemplo: "estoy investigando el paso de la fotografía a las tres dimensiones", o "estoy estudiando sobre tal tema", o "estoy preparando mi próxima muestra", etc. Pero esas son respuestas protocolares, no ahondan en los problemas y no sirven para los períodos en los que no se está haciendo nada.

El asunto es que el arte -que posee un sistema de intercambio propio basado en el comercio-, por absurdo que suene, no es considerado en algunos entornos como una profesión. Y esto también conlleva la incomodidad de no poder explicar a qué le dedicamos nuestro tiempo, energía y desvelos.

En Latinoamérica, como supongo que también sucederá en otras regiones de características socio-económicas similares, los artistas suelen tener otro trabajo complementario: el trabajo que paga el alquiler. Muchas veces vinculado a la docencia, a la gestión, o a servicios asociados como montaje de exposiciones, revelado, asistencia a otros artistas, realización, enmarcado, entre otros. Y es que producir obra en regiones como esta también significa adaptarse a ciertas condiciones de trabajo, ya que un artista o un intelectual aquí normalmente no puede producir de manera estable, y por eso mismo, ni siquiera puede afirmar cabalmente que, en ciertas condiciones, lo que hace sea un trabajo.

En mi opinión, sabiéndonos conscientes de estar atravesados por estas coyunturas propias de nuestra escena local, nos queda la tarea de reconocer el vigor propio de producir con los pies sobre este territorio. Pudiendo asimilar la -no poco controversial- idea de periferia si así nos conviniera, manifestando proclividad hacia las contradicciones de "lo contemporáneo" de manera crítica, transgresiva y hasta con humor. De este abordaje, inspirado en la diferencia cultural no como fuerza estática sino transformadora, valorando las necesidades y oportunidades en términos que no son únicamente los del mercado, puede surgir una práctica entendible en nuestros propios términos, que son los que deben contar en última instancia.

\section{Un animal que hurga}

Crear hoy, en cualquier disciplina artística, implica la búsqueda de entender un sistema de producción personal. En este proceso hay que bancarse momentos de "no existencia", de pensar algo, buscarlo, obsesionarse, pero no pretender encontrarlo. Ese acto de fe es parte de ser artista. Atesorar la inutilidad de los actos (hoy en día que todo debe tener un propósito y un rédito) esconde algo muy bello. Significa saberse consciente de que no se es completamente consciente, sostener un vínculo no sabiéndolo todo.

Cómo comunicar la obra es el verdadero problema, porque ahí se juega algo muy profundo del acto de creación. "La obra es producto de un deseo irreprimible de decir y de un deseo igualmente irreprimible de callar o esconder"(Frémon, 2008, p.22). Eso arma un circuito simbólico que se concretiza en el otro. La tensión de la obra es el resultado de ese conflicto que se emplaza entre lo que se quiere decir y lo que se prefiere callar.

Entonces, en la decisión de hacer circular el trabajo se juega la responsabilidad de que estar produciendo arte es estar produciendo un discurso. Cuantas más herramientas ten- 
gamos para poder pensar el trajo propio y para poder decidir qué queremos hacer con esto que producimos, más posibilidades tendremos de encontrar un sistema a lo largo de la carrera. Algo así como una manera de trabajar que va estableciendo una lógica que se despliega en el tiempo.

Históricamente, los artistas han buscado métodos para aproximarse a los problemas de los tiempos que les tocó vivir, como un animal que hurga cediendo al instinto de buscar. Lo que se desea en esta búsqueda por el método es lograr calar un tajo que habilite la comunicación con la sensibilidad de los pares. Y, en el mejor de los casos, redactar el propio informe sobre el estado en que se encuentra el espíritu de cada época.

\section{Lista de Referencias Bibliográficas}

Berger, Y., Berger J., Favre Emmanuel. (2015). Desde el taller, Barcelona: Editorial Gustavo Gili.

Cohen, L. (30 de octubre de 2011). Una voz en la tierra. Página 12. Recuperado de: https:// www.pagina12.com.ar/diario/suplementos/radar/9-7427-2011-10-30.html

Cheng, F. (2016). Vacío y plenitud, Madrid: Ediciones Siruela.

Damisch, H. (2007). El desnivel: la fotografía puesta a prueba, Buenos Aires: La Marca Editora.

Frémon, J. (2008). Louise Bourgeois. La mujer casa, Barcelona: Editorial Alba.

Groys, B. (2014). Volverse público. Las transformaciones del arte en el ágora contemporánea, Buenos Aires: Caja Negra.

Jastreblansky, M. La fotografía, una Bella Arte, disponible en: https://www.lanacion.com. ar/1000185-la-fotografia-una-bella-arte. Consultado el 07/08/2018

Lemagny, Jean-Claude. (2008). La sombra y el tiempo. La fotografía como arte, Buenos Aires: La Marca editora.

Marcadé, B. (2008). Marcel Duchamp. La vida a crédito, Buenos Aires: Libros del Zorzal.

The Velvet Underground, (1969), Some Kinda Love, en The Velvet Underground [CD], Hollywood: MGM Records.

Wenders, W. (2016). Los píxeles de Cézanne y otras impresiones sobre mis afinidades artísticas, Buenos Aires: Caja Negra.

\section{Bibliografía}

Chéroux Clément y Jones Julie editores. (2015). Henri Cartier-Bresson. Ver es un todo, entrevistas y conversaciones 1951-1998, Barcelona: Editorial Gustavo Gili.

González, V. (2011). Fotografía en la Argentina. 1840-2010, Buenos Aires: Fundación Alfonso y Luz Castillo.

Guasch, A. M. (2001). El arte último del Siglo XX. Del posminimalismo a lo multicultural, Madrid: Alianza Editorial S.A. 
Hess, W. (2008). Documentos para la comprensión del arte moderno, Buenos Aires: Nueva Visión.

Iturbide, G., García-Alix, A., Rio Branco Miguel, Bleda y Rosa, Gonnord Pierre y Serrano Andrés. (2010). Conversaciones con fotógrafos. Lo real, Madrid: La Fábrica.

Laddaga Reinaldo. (2006). Estética de la emergencia. La formación de otra cultura de las artes, Buenos Aires: Adriana Hidalgo Editora.

Abstract: This article proposes a reflection about the creation processes in visual arts, focusing on argentine photography. The ways to reach the artwork and develop the act of creation are multiple and personal. The proposal is to look at the local scene and think about its particularities, its specific features and problems.

Keywords: photography - artistic creation - process - visual arts

Resumo: Este artigo investiga a reflexão sobre alguns aspectos relacionados com os processos de criação artística em artes visuais e especificamente em fotografia de Argentina. Obter formas de trabalhar e desenvolver o ato de criação são múltiplos e pessoais.

Palavras chave: Processos - artes visuais - criação

[Las traducciones de los abstracts fueron supervisadas por el autor de cada artículo] 